Dossiê - Para além do “ativismo judicial” e da “judicialização da política” DOI: $10.5433 / 2176-6665.2016 \mathrm{v} 21 \mathrm{~N} 1 \mathrm{P} 236$

\title{
As associações de Classe e o Controle de Constitucionalidade das Leis via ADPFs
}

\author{
Igor Suzano Machado ${ }^{1}$, Louise Siqueira Tavares ${ }^{2}$, \\ Gustavo Zenha Cordeiro ${ }^{3}$ e Bruno Oliveira ${ }^{4}$
}

\begin{abstract}
Resumo
O presente trabalho buscou analisar a atuação das associações de classe na proposição de ações de controle de constitucionalidade das leis. Além de se destacarem por provocarem o controle de constitucionalidade via sociedade civil, as associações de classe também se mostram interessantes por envolverem grupos com interesses potencialmente antagônicos, como empresários e trabalhadores. Daí a intenção de estudar seus padrões de atuação no que concerne ao uso das Arguições de Descumprimento de Preceito Fundamental, em que são questionados atos do poder público atentatórios contra a Constituição naquilo que tais associações consideram como seus ditames mais importantes.
\end{abstract}

Palavras-chave: Controle de constitucionalidade. Associações de classe. ADPF. Judicialização da política.

1 Professor-adjunto do Departamento de Ciências Sociais da Universidade Federal do Espírito Santo (UFES), Brasil. igorsuzano@gmail.com

2 Graduanda em Ciências Sociais pela Universidade Federal de Viçosa (UFV), Brasil. louise. tavares@ufv.br

3 Graduando em Ciências Sociais pela Universidade Federal de Viçosa (UFV), Brasil. zenhas@ gmail.com

4 Bacharel em Ciências Sociais pela Universidade Federal de Viçosa (UFV), Brasil. brunoft. oliveira@gmail.com 


\title{
Class Associations and Brazilian Judicial Review By "ADPFs"
}

\begin{abstract}
This study aims to analyze the performance of a specific group among the legitimate to mobilize the judicial review: the class associations. In addition to belong to civil society, the professional associations also show themselves interesting as they involve groups with potentially opposing interests, as entrepreneurs and workers. Then, the intention is to study their performance regarding the use of ADPFs - Pleas of violation of constitutional fundamental statements - that are a mean of judicial review against laws which violate the Constitution in what such associations regard as its most important dictates.
\end{abstract}

Keywords: Judicial review. Class association. ADPF. Judicialization of politics.

\section{INTRODUÇÃO $0^{5}$}

Objetivo da presente pesquisa é examinar como o texto constitucional tem sido interpretado por aqueles grupos que poderiam ter alguns dos interesses mais contrastantes dentre aqueles considerados como "intérpretes legítimos" 6 da Constituição, isto é: as associações de classe. E isso seria pensado não na sua atuação política pela via legislativa, em que os representantes dos agrupamentos profissionais pressionariam por mudanças legais capazes de alterar o sentido da constituição, mas na sua atuação via controle de constitucionalidade das leis pelo Judiciário. Ou seja, o estudo pretende avaliar como as entidades de classe têm fomentado o que alguns autores convencionaram chamar de "judicialização da política" - isto

5 Os autores do artigo agradecem à FAPEMIG pelo suporte financeiro para a realização da pesquisa, por meio da bolsa de iniciação científica concedida.

6 De acordo com a Constituição, são considerados "intérpretes legítimos da constituição", isto é, podem dar início a uma ação de controle de constitucionalidade: o Presidente da República; a Mesa do Senado Federal; a Mesa da Câmara dos Deputados; a Mesa de Assembléia Legislativa ou da Câmara Legislativa do Distrito Federal; o Governador de Estado ou do Distrito Federal; o Procurador-Geral da República; o Conselho Federal da Ordem dos Advogados do Brasil; partido político com representação no Congresso Nacional; confederação sindical ou entidade de classe de âmbito nacional. 
é, a transfusão de pautas políticas para sua resolução nos tribunais, em especial tribunais constitucionais - para fazerem valer sua forma própria de compreender o sentido por vezes polissêmico do texto constitucional, inclusive contra prescrições do Executivo e do Legislativo.

Desde o trabalho pioneiro de C. Neal Tate e Torbjörn Vallinder (1995), a expressão "judicialização da política" tornou-se parte do vocabulário de estudos sobre a relação entre a política e a justiça, inclusive no Brasil. Conforme destaca Ran Hirschl (2008, p. 119-123), a expressão tornou-se uma espécie de termo "guardachuva", para representar uma miríade de situações distintas. Ela se debruça, segundo o autor, especialmente sobre três processos interrelacionados. Primeiramente, no nível mais abstrato, refere-se à disseminação do discurso, jargão, regras e processos jurídicos na esfera política e na formulação de políticas públicas - que muitos preferem se referir em termos de "juridificação". Em segundo lugar, num nível mais concreto, diz respeito à extensão da província de atuação dos juízes na formulação de políticas públicas e organização da burocracia e órgãos políticos, inclusive mediante atuação na defesa de direitos e garantias individuais, de forma a restringir a atuação dos poderes Executivo e Legislativo. Por fim, há ainda casos de judicialização da "megapolítica", em que juízes chegam a definir questões relativas à segurança nacional, planejamento econômico, processo eleitoral, etc.

A amplitude de temas relacionados ao guarda-chuva da judicialização gerou críticas, como a de que se trataria de um "conceito pouco preciso, mas de rápida circulação pública" (MACIEL; KOERNER, 2002, p. 131), ou mesmo, "um nome atribuído a partir do início dos anos noventa ao protagonismo político de juízes, o qual não apresentava qualquer novidade e não tinha implicações fundamentais para as democracias contemporâneas", tratando-se de uma expressão "teoricamente inválida, porque apresenta deslizes conceituais, ao 
simplificar as relações entre os tribunais e a política, revelando uma concepção estreita da jurisdição e do direito" e apresentando "uma abordagem parcial e enviesada sobre as transformações dos Estados contemporâneos" e "ambiguidades sobre seu campo de aplicação" que a tornariam analiticamente inútil (KOERNER; INATOMI; BARATTO, 2011, p. 176-177).

Consequentemente, estudos mais específicos, mesmo que não necessariamente descartem completamente a expressão, têm tentado lhe dar contornos mais críticos, ressaltando dimensões como a importância de processos de "juridificação", por exemplo, capitaneados pelo Ministério Público, que, contudo, não chegam à efetiva "judicialização" ao não abraçarem a litigância formal (ASENSI, 2008). Ou então, chamando atenção para, pelo contrário, os efeitos posteriores e reflexos da efetiva judicialização, por exemplo, mediante a reação dos poderes Executivo e Legislativo às decisões das cortes constitucionais (POGREBINSCHI, 2012). Mesmo Luiz Werneck Vianna e Marcelo Burgos, cujos trabalhos pioneiros ajudaram a popularizar a expressão "judicialização da política" no Brasil (VIANNA et al., 1999), colocaram em destaque, em discussão mais específica sobre ações civis públicas, a noção mais precisa "procedimentalização do direito" (VIANNA, BURGOS, 2003).

Tentando evitar ainda um certo viés "de cima para baixo" contido nos estudos sobre a judicialização, que dedicariam demasiada atenção à ação especificamente dos juízes e tribunais, há ainda autores, no Brasil (LOSEKANN, 2013; MACIEL, 2011) e fora do país, que apostam na noção de "mobilização do direito". Tal noção visaria prestar mais atenção às demandas da sociedade civil, sob um ponto de vista, digamos, "de baixo para cima", seja focando os litigantes individuais, seja em frutífero diálogo com a literatura sobre movimentos sociais em demandas coletivas (McCANN, 2008, p. 523). 
O presente estudo foca um tema clássico dos estudos sobre a judicialização da política: o controle de constitucionalidade das leis pelo Judiciário. Contudo, contrariamente à literatura erigida sobre tal referência (MACIEL, 2011, p. 99), não está prioritariamente interessado no chamado "ativismo judicial". Em consonância com os estudos sobre a mobilização do direito, prestará mais atenção às demandas dos litigantes que provocam a jurisdição constitucional, mesmo que tais demandas ainda não tenham sido apreciadas. Ainda assim, agora em falta com os estudos sobre mobilização do direito, não haverá o nível de acompanhamento sistemático dos litigantes estudados para além da ação judicial, como forma de verificar suas motivações instrumentais e os resultados de configurações simbólicas derivados de suas ações dentro e fora dos tribunais. De qualquer forma, estará em foco a "invocação pública de normas jurídicas para a regulação de conflitos e comportamentos" indicando "a ação de indivíduos, grupos ou organizações na promoção de reivindicações legais por meio das quais interesses, valores e demandas são traduzidos como questão de direitos" (ZEMANS apud MACIEL, 2011), numa espécie de "sinédoque constitucional", 7 representativa de uma categoria analítica sociológica de inspiração gramsciana que subjaz tanto estudos sobre a judicialização da política (HIRSCHL, 2008, p. 137), quanto sobre a mobilização de direitos (McCANN, 2008, p. 530): a categoria "hegemonia", um termo referente ao conjunto de meios pelos quais a sociedade produz consenso e assegura a ordem, de forma que, nas palavras de Gramsci, uma dada classe social supera seus interesses meramente corporativos em prol de uma atitude dirigente, capaz de guiar intelectual e moralmente a sociedade como um todo.

Para fazer uso de um vocabulário contemporâneo que atualiza a noção gramsciana clássica, as práticas hegemônicas seriam operações

7 A sinédoque é uma espécie de metonímia que expressa a representação do todo por uma de suas partes. 
de sinédoque, em que uma parte da sociedade a representaria como um todo. Fazendo uso de significantes de tendencial vacuidade, os grupos sociais articulariam determinados discursos e uma série de elementos discursivos em cadeias de significação capazes de dar à totalidade inteligibilidade. Por exemplo, o princípio da igualdade é representativo muito mais de uma totalidade ausente do que de uma objetividade pré-determinada. Trata-se de um significante vazio, pois só existe em suas manifestações concretas, mas não se confunde com elas, permitindo que vários grupos - ou seja, várias dessas manifestações concretas - disputem a posição de preencher o vazio desse significante e, consequentemente, a hegemonia construída em torno do mesmo (LACLAU; MOUFFE, 2006).

Lida sob essa ótica, o Direito passa a ser uma construção hegemônica. A atividade jurisdicional assim, deixa de ser caracterizada catacreticamente como a atividade de uma mera "boca da lei", tal como queria Montesquieu, e, consequentemente, não pode ser lida sob um ponto de vista estritamente formalista. Pelo contrário, ela passa a ser entendida como parte de uma ação política estratégica que visa a obtenção da hegemonia.

Várias são as ações de controle de constitucionalidade das leis no Brasil, responsáveis por levar demandas políticas à discussão ou rediscussão no Judiciário, mais especificamente, no Supremo Tribunal Federal (STF). O grosso desse controle de constitucionalidade, chamado "controle de constitucionalidade concentrado"8 é feito por meio das Ações diretas de inconstitucionalidade (ADINs). Por isso, em geral, o controle de constitucionalidade das leis no Brasil, é estudado

8 O chamado controle de constitucionalidade concentrado (ou em abstrato) é aquele em que se provoca diretamente o STF, buscando anular lei específica. Ele se diferencia do chamado controle de constitucionalidade difuso (ou em concreto), que é aquele que pode ser realizado por qualquer juiz, em causa específica que chegue a seu julgamento, invalidando não a lei, mas sua aplicação aos envolvidos naquela causa. O controle de constitucionalidade difuso não será objeto de estudo do presente trabalho. 
tomando como base tais ações. ${ }^{9} \mathrm{O}$ presente estudo, no entanto, opta por analisar um conjunto de ações diferente, capaz, talvez, de mostrar um quadro de utilização também diferente. Trata-se das Arguições de Descumprimento de Preceito Fundamental (ADPFs), uma ação de controle de constitucionalidade utilizada em contingente bem menor que as ADINs, que teria algumas características distintivas, cuja análise despertara o interesse dos pesquisadores. Concentrandose nos chamados preceitos constitucionais fundamentais, tratar-se-ia de ação que, de um lado, poderia estar mais concentrada na defesa de direitos - o que não é o foco da maior parte do nosso controle de constitucionalidade via ADINs (COSTA; BENVINDO, 2014; VIANNA et al., 1999) - e, de outro, apelaria mais fundamentalmente às normas jurídicas classificadas como "princípios", ${ }^{10}$ que são normas de interpretação mais aberta, que poderiam ensejar entendimentos potencialmente mais diversificados, a depender do grupo responsável por mobilizar seu conteúdo em proveito próprio - potencialmente próximas ao que anteriormente foi caracterizado, sob uma terminologia laclauniana, como "significantes vazios".

Logo, o objetivo principal da pesquisa refere-se à análise da relação entre as ADPFs e a sociedade civil organizada, fazendo-nos selecionar, para a análise, as ADPFs propostas pelas associações de classe e confederações sindicais. Ainda que, pelo menos no que tange ao funcionamento das ADINs, já se saiba que as associações de classe,

9 É o caso dos já citados estudos de Luiz Werneck Vianna et al. (1999) e Thamy Pogrebinschi (2012), assim como do abrangente estudo capitaneado por Alexandre Araújo Costa e Juliano Zaiden Benvindo (2014).

10 Essa classificação atende principalmente à distinção das normas jurídicas entre princípios e regras. As regras teriam aplicação na modalidade tudo ou nada: ocorrendo o fato nela descrito, ela deverá incidir, não podendo coexistir, portanto, no mesmo sistema jurídico, regras com conteúdo contraditório. Já os princípios, indicariam uma direção, um valor, ou um fim, sendo possível a existência de princípios potencialmente colidentes num mesmo sistema jurídico, que, assim, apenas indicam para que lado a decisão deve "pesar" naquele caso, podendo esse peso pender para o outro lado em uma situação diferente daquela (DWORKIN, 2002, p. 35$50)$. 
apesar de muito atuantes, possuem baixo grau de sucesso em suas demandas (HARTMAN; FERREIRA; REGO, 2016), o objetivo do trabalho não é avaliar o sucesso ou insucesso de tais demandas, mas focar as lógicas e potencialidade subjacentes à mobilização do controle de constitucionalidade das leis dentro de sua faceta mais democrática, posto que provocada, de certa forma, de "baixo para cima", em direção ao ideal do que Peter Häberle (2002) chamara de "comunidade aberta dos intérpretes da Constituição".

\section{Metodologia}

A pesquisa em questão debruçou-se sobre as ADPFs disponíveis no sítio do STF (www.stf.jus.br) em versão digital. Tratase, pois, de uma pesquisa centrada em análise documental que se desmembrou em duas principais etapas: 1) Coleta, catalogação e análise quantitativa das ações e; 2) Estudos de caso de cunho qualitativo. $\mathrm{O}$ processo de catalogação das ADPFs disponíveis no sítio eletrônico do STF abrangeu as ações desde a regulamentação desse instrumento pela lei número 9.882 em 1999, até o 25ํaniversário da Constituição, em outubro de 2013. Tendo isso em vista, o processo de catalogação foi iniciado a partir da leitura da página de rosto de cada ação com o propósito de identificar o seu proponente. Aquela cujo proponente se tratava de uma associação de classe ou confederação sindical era selecionada para posteriormente ser submetida a classificações a fim de conformar o banco de dados.

Após a seleção das arguições cujos proponentes se tratavam de entidades de classe, partiu-se para a construção do banco de dados a partir da classificação de tais ações em função de dados coletados nos documentos eletrônicos, dentre os quais: o requerente, o requerido (isto é, o poder político questionado entre Executivo Federal, Legislativo Federal, Judiciário Federal, Executivo estadual, Legislativo Estadual, 
Judiciário Estadual, Executivo municipal e Legislativo Municipal - com uma ação classificada como "outros" por ter sido ajuizada contra conselho profissional), se apresentava resultado de liminar, se dispunha de decisão final, e, por fim, a temática da referida ação.

A classificação dos temas abordados nas arguições teve como base as categorias constantes em A Judicialização da Política e das Relações Sociais no Brasil organizado por Luiz Jorge Werneck Vianna, Maria Alice Rezende de Carvalho, Manuel Palacios Cunha Melo e Marcelo Baumann Burgos. Assim, as ADPFs foram agrupadas em sete categorias já presentes nos estudos de Werneck Vianna et al. (1999, p. 63-64), de acordo com a temática sobre a qual versavam, enquadrandose em um dos seguintes grupos:
a ) Administração Pública;
b) Política Social;
c ) Regulação Econômica;
d) Política Tributária;
e ) Regulação da Sociedade Civil;
f ) Competição Política;
g) Relações de Trabalho.

Todavia, como o presente trabalho concentrou-se na análise de somente uma das formas de controle concentrado de constitucionalidade das leis, as ADPFs, em detrimento da ação estudada em Judicialização da política e das relações sociais no Brasil a ADIN - foram realizadas pequenas alterações nessas categorias. Consequentemente, dadas as particularidades do objeto da presente pesquisa, acrescentamos à categoria "regulação econômica" normas que dizem respeito a monopólios estatais. À categoria "regulação da sociedade civil" incluímos normas que se referem à regulação para bens difusos/coletivos e a benfeitorias urbanas. À categoria "administração pública", por sua vez, adicionamos também normas que tratam de concessões e autorizações. Por fim, duas ações tiveram 
seu tema classificado como "outros", pois tais ADPFs foram utilizadas como recursos contra aspectos formais de decisões judiciais ou administrativas, não possuindo propriamente um tema substantivo.

A segunda etapa, por sua vez, refere-se à análise de teor qualitativo de 10 ADPFs selecionadas para estudos de caso. Tais ações foram selecionadas de acordo com o peso relativo de cada tipo de associação no quantitativo geral de ADPFs, com as associações com mais ações ajuizadas, contando também com mais ações selecionadas para esta etapa da pesquisa. Além disso, com base nas estatísticas que serão expostas a seguir, buscou-se analisar ações que contassem com casos típicos, no que tange ao poder político e tema enfrentados por aquele grupo de associações. Por fim, também foi dada preferência para ações que já contassem com alguma decisão por parte do tribunal, para que pudesse ser avaliada também a posição dos juízes, que, ainda que não sejam o foco da pesquisa, podem indicar aspectos importantes acerca das possibilidades de aceitação das demandas judicializadas pelas associações de classe.

Logo, como as associações de empresários são as associações que mais ajuizaram ações no período dos 25 anos da Constituição de 1988, foram selecionadas quatro ADPFs com este tipo de requerente, a saber, as ADPFs de número 46, 95, 127 e 151. Optou-se pela ADPF de número 46, pois apresenta discussão sobre o tema típico das ações ajuizadas por associações de empresários, isto é, Regulação Econômica. A ADPF número 95 fora escolhida por abordar decisão contrária a um poder recorrentemente questionado por tais associações, ou seja, o Executivo Federal. Ambas as ações, além do mais, possuem decisão final - o que se mostrou raro haja vista a recente regulamentação desse instrumento de controle concentrado de constitucionalidade. Já as ADPFs de número 127 e 151, foram selecionadas uma vez que apresentam decisões distintas de liminar, posto que a ação número 127 dispõe de decisão de liminar indeferida, enquanto a arguição 
de número 151 apresenta decisão de liminar deferida. Ademais, essas ações foram mobilizadas contrariamente ao Executivo Federal, recorrentemente questionado pelas associações de empresários.

As associações de funcionários públicos também mobilizaram ADPFs com certa frequência, o que fez com que fossem escolhidas três ações para estudo de caso. Assim, foram selecionadas as ADPFs de número 41, 90 e 97. Escolheu-se a ADPF de número 41 por abordar a temática administração pública mobilizada contra o Judiciário Estadual; a 90 e a 97, por sua vez, foram selecionadas porque apresentam decisão final.

No que tange à atuação das associações de trabalhadores, esta será analisada mediante o estudo das ADPFs número 54 e 14. Isso porque a arguição 54 apresenta decisão final e a ADPF de número 14 apresenta resultado da liminar.

Por fim, no que se refere ao comportamento das associações de profissionais liberais, optou-se pela análise de apenas uma ADPF, a ação de número 112. Isso se justifica pelo fato de tal arguição abarcar o tema e poder político mais constantemente acionados por essas associações, ou seja, o tema da regulação da sociedade civil e o Poder Executivo Federal.

\section{As ADPFs de Cada Tipo de Associação: Quadro geral}

Nesta seção analisaremos a atuação de cada tipo de associação sob a luz de dois principais pontos: 1) em vista dos poderes políticos por elas enfrentados e 2) Quanto aos temas por elas abordados. A análise dessas dimensões das ADPFs das associações de classe, resulta no quadro geral exposto a seguir.

Quanto aos poderes públicos questionados pelas ações, o quadro é o expresso na tabela e gráfico abaixo: 
QUADRO 1

\begin{tabular}{|c|c|c|c|c|}
\hline $\begin{array}{c}\text { Tipo de } \\
\begin{array}{c}\text { Associação X } \\
\text { Poder público } \\
\text { questionado }\end{array}\end{array}$ & $\begin{array}{c}\text { Associações de } \\
\text { trabalhadores }\end{array}$ & $\begin{array}{c}\text { Associações de } \\
\text { empresários }\end{array}$ & $\begin{array}{c}\text { Associações de } \\
\text { funcionários } \\
\text { públicos }\end{array}$ & $\begin{array}{c}\text { Associações de } \\
\text { profissionais } \\
\text { liberais }\end{array}$ \\
\hline Executivo Federal & 7 & 11 & 4 & 3 \\
\hline Executivo Estadual & 1 & 3 & 9 & 2 \\
\hline $\begin{array}{c}\text { Executivo } \\
\text { Municipal }\end{array}$ & 1 & 5 & 0 & 0 \\
\hline Legislativo Federal & 1 & 0 & 0 & 0 \\
\hline $\begin{array}{c}\text { Legislativo } \\
\text { Estadual }\end{array}$ & 0 & 0 & 0 & 1 \\
\hline $\begin{array}{c}\text { Legislativo } \\
\text { Municipal }\end{array}$ & 1 & 7 & 2 & 1 \\
\hline Judiciário Federal & 4 & 1 & 0 & 0 \\
\hline Judiciário Estadual & 0 & 32 & 20 & 7 \\
\hline Outros & 0 & & & 0 \\
\hline Total & 15 & 1 & 0 & \\
\hline
\end{tabular}

\section{Gráfico 1}

Poderes políticos questionados pelas Associações de classe

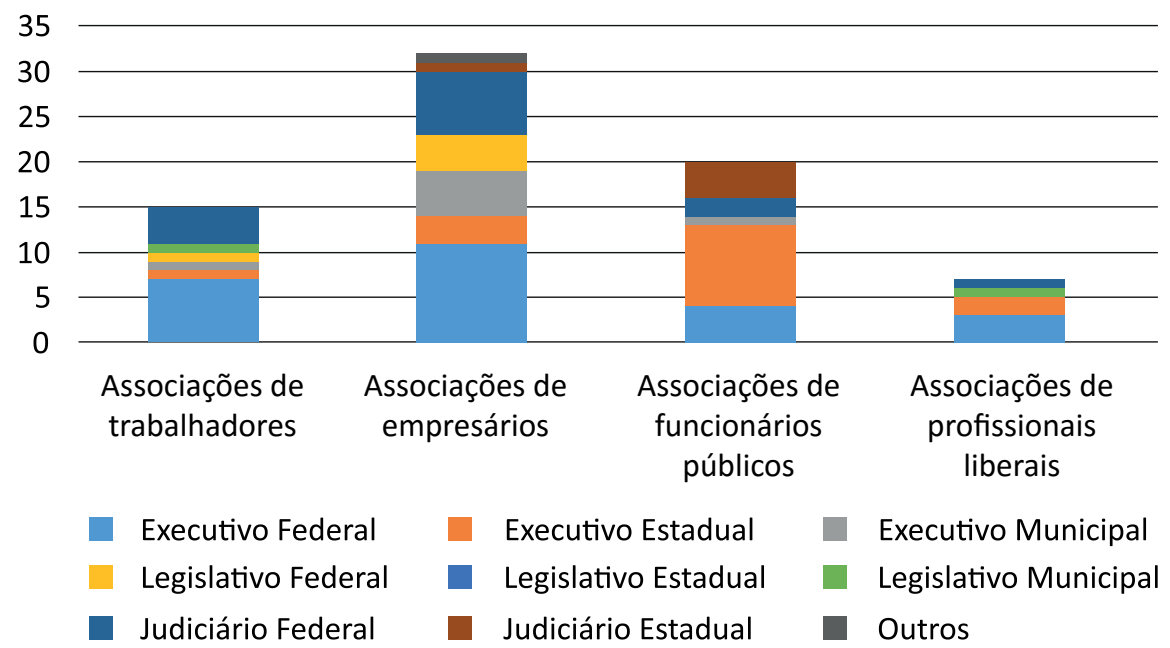


Pelo que se pode perceber dos dados acima, temos que o Executivo Federal foi o Poder mais questionado pelas associações de trabalhadores, que ajuizaram 7 ações contra ele de um total de 15 - o que corresponde à quase $50 \%$ de todas as ações mobilizadas ao longo de 13 anos. O segundo Poder mais questionado por esse tipo de associação foi o Judiciário Federal, que sofreu 4 arguições.

O poder político mais enfrentado pelas associações de empresários, também foi o Executivo Federal, com 11 ações mobilizadas contra ele, em um total de 32. Em segundo lugar, encontrase o Judiciário Federal, contra o qual se instauraram 7 arguições. $\mathrm{O}$ Executivo Municipal, por sua vez, ficou em terceiro lugar, com 5 ações.

Já as associações de funcionários públicos mobilizaram ADPFs em maior número contra o Poder Executivo Estadual, contra o qual foram mobilizadas 9 ações. Atrás dele encontram-se igualmente os Poderes Executivo Federal e o Judiciário Estadual, ambos questionados em 4 arguições.

Por fim, as associações de profissionais liberais mais se opuseram às determinações do Executivo Federal, contra o qual foram ajuizadas 3 arguições. O Executivo Estadual, por sua vez, fora mobilizado através de 2 ações.

Já no que tange aos temas abordados pelas diferentes associações de classe, o que se observa é o constante na tabela e gráfico que seguem:

QUADRO 2

\begin{tabular}{|c|c|c|c|c|}
\hline $\begin{array}{c}\text { Tipo de } \\
\text { Associação X } \\
\text { Tema enfrentado }\end{array}$ & $\begin{array}{c}\text { Associações } \\
\text { de } \\
\text { trabalhadores }\end{array}$ & $\begin{array}{c}\text { Associações } \\
\text { de } \\
\text { empresários }\end{array}$ & $\begin{array}{c}\text { Associações de } \\
\text { funcionários } \\
\text { públicos }\end{array}$ & $\begin{array}{c}\text { Associações de } \\
\text { profissionais } \\
\text { liberais }\end{array}$ \\
\hline $\begin{array}{c}\text { Administração } \\
\text { pública }\end{array}$ & 3 & 6 & 19 & 1 \\
\hline Política social & 3 & 0 & 0 & 0 \\
\hline $\begin{array}{c}\text { Regulação } \\
\text { econômica }\end{array}$ & 1 & 11 & 0 & 0 \\
\hline
\end{tabular}




\begin{tabular}{|c|c|c|c|c|}
\hline Política tributária & 3 & 4 & 0 & 1 \\
\hline $\begin{array}{c}\text { Regulação da } \\
\text { sociedade civil }\end{array}$ & 3 & 9 & 0 & 2 \\
\hline $\begin{array}{c}\text { Competição } \\
\text { política }\end{array}$ & 0 & 0 & 0 & 0 \\
\hline $\begin{array}{c}\text { Relações de } \\
\text { trabalho }\end{array}$ & 2 & 0 & 1 & 1 \\
\hline $\begin{array}{c}\text { Utilização como } \\
\text { recurso }\end{array}$ & 0 & 32 & 20 & 7 \\
\hline Total & 15 & & & \\
\hline
\end{tabular}

GrÁFICO 2

Temas abordados pelas Associações de classe

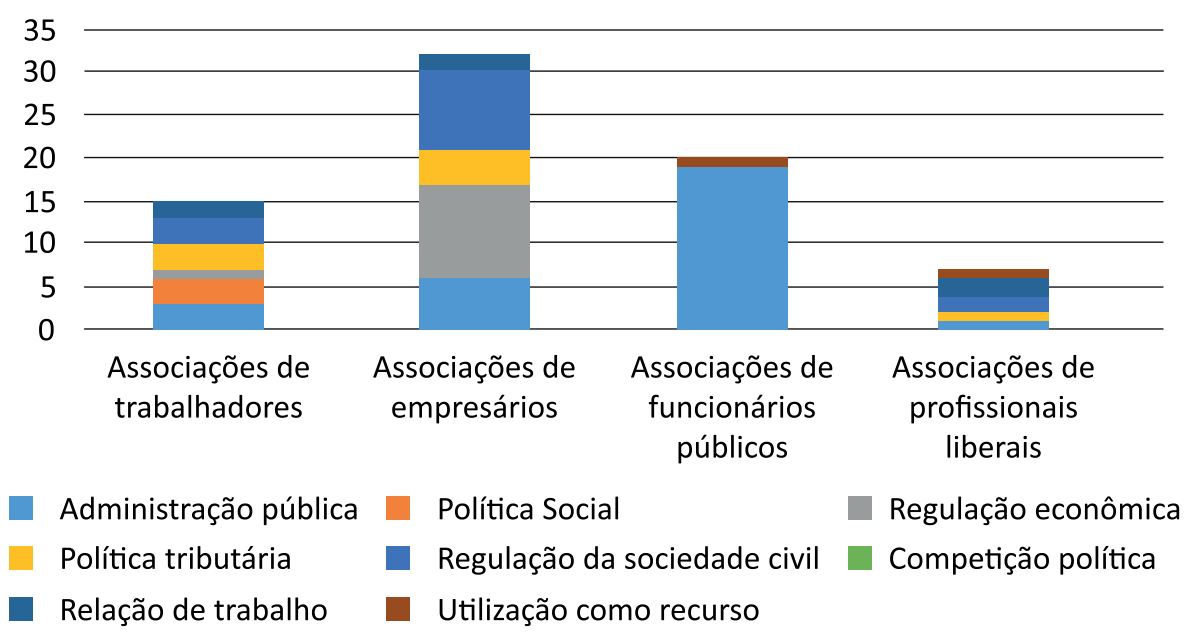

Do quadro exposto acima percebe-se que os temas mais abordados pelas arguições ajuizadas pelas associações de trabalhadores foram igualmente administração pública, política tributária, regulação da sociedade civil e política social, todos os quais com 3 ações cada um. A isso se somaram 2 ações sobre relação de trabalho e 1 acerca de regulação econômica.

Já o tema mais mobilizado pelas associações de empresários foi a regulação econômica, representada por 11 ações de um total de 
32, equivalendo a $34,4 \%$. Regulação da sociedade civil foi a segunda temática mais mobilizada por essa categoria, com 9 arguições durante o período estudado. Atrás desses dois temas, aparece o tema da administração pública, que contou com 6 ações.

Quanto aos temas das arguições das associações de funcionários públicos, a regularidade leva quase que a um tema único, já que, de um total de 20 arguições, como era e se esperar, 19 abordaram temáticas referentes à administração pública. A ação classificada como "outros", inclusive, questionava aspectos formais de um processo administrativo, estando, portanto, também relacionada ao tema da administração pública.

Por fim, dentre as 7 ações mobilizadas pelas associações de profissionais liberais, as temáticas que mais apareceram foram a regulação da sociedade civil e as relações de trabalho, ambas as quais com 2 ADPFs cada.

De acordo com o que foi apresentado anteriormente, e apesar das limitações inerentes a um estudo estatístico que conta com relativamente poucos casos, pode-se deduzir que as particularidades jurídicas da $\mathrm{ADPF}^{11}$ e os interesses dos grupos que as mobilizam parecem ser as melhores variáveis explicativas para os dados levantados. Isto porque, por não serem aplicáveis somente a atos normativos, abrangendo também outros atos do poder público, as ADPFs surgem como instrumento importante para o questionamento

11 Conforme asseverado por Barroso (2008), afim de assegurar a harmonia do ordenamento jurídico brasileiro, elaborou-se o mecanismo das ADPFs com a finalidade de superar as lacunas oriundas da ADIN, a qual não pode ser mobilizada contra leis anteriores à Constituição de 1988 nem contra atos do Poder público Municipal. Além disso, a regulamentação das ADINs abarca atos normativos, ao passo que a das ADPFs abrange atos do poder público - que são mais extensivos que ato normativo - o que lhe permite incluir decisões judiciais reiteradas, contratos administrativos e resoluções. Ademais, a proposição de ADPFs somente é viável quando não é possível sanar a suposta lesão ao preceito fundamental por outros meios, isto é, mobiliza-se a ADPF apenas quando não se pode ajuizar ADIN nem Ação Declaratória de Constitucionalidade (ADC) - é o chamado requisito da subsidiariedade. 
de atos do poder Executivo, como decretos e portarias, e do poder Judiciário, como sentenças e acórdãos, que não podem ter sua constitucionalidade questionada por via de ADINs. Não à toa, tais poderes aparecem como aqueles que são mais vezes questionados pelas ADPFs das associações de classe.

Além disso, dados os interesses específicos dos autores das ADPFs, certos temas aparecem como prioritariamente enfrentados. Isto é bastante nítido, por exemplo, quando, conforme o esperado, as associações de funcionários públicos ajuízam ações quase em sua totalidade voltadas para o tema da administração pública. As associações de empresários, por sua vez, tendem a questionar atos do poder público que possam constranger suas atividades econômicas, notadamente na política econômica, e na regulação da administração pública - por exemplo, no que tange aos contratos públicos entre governo e iniciativa privada - e da sociedade civil - por exemplo, no que tange a restrições de exploração do meio ambiente e do espaço urbano.

\section{Estudos de Caso}

Não obstante as inferências possíveis de serem retiradas do quadro geral apresentado acima, por meio de análise quantitativa, não é possível extrair de tais dados algumas informações importantes, contidas em nuances que só podem ser percebidas com uma leitura mais cuidadosa do material textual das ações. Tendo isso em vista, visando captar tais nuances, a presente pesquisa irá se dedicar, a partir de agora, a estudos qualitativos do teor das ações, complementando o quadro geral quantitativo delineado nesta primeira parte, com dados mais específicos sobre certas ações, capazes de fornecer indícios importantes de como as associações de classe têm mobilizado as ADPFs, por exemplo, no que tange aos tipos de argumentos utilizados, 
e possíveis diferentes entendimentos do que sejam os preceitos verdadeiramente fundamentais da atual Constituição brasileira.

Quando a pesquisa teve início, imaginamos que a opção pelas ADPFs nos levaria a ações que mobilizassem princípios jurídicos abstratos. Contudo, regras bastante específicas, como a proibição de vinculação ao salário mínimo ou regras de competência legislativa foram constantemente utilizadas. Também era esperado a mobilização de uma suposta vontade coletiva como força motriz das arguições, o que foi observado algumas vezes, mas não apareceu exatamente como regra.

Contudo, três tendências aparecem nitidamente nas análises retratadas anteriormente. Primeiramente, a busca de concretização de interesses próprios das associações, seja com a associação se apresentand o como titular de uma vontade coletiva que transcende sua própria categoria, ou não. Em segundo lugar, a disputa por recursos escassos também teve destaque e apareceu com nitidez em várias ações. Por fim, a construção de uma narrativa de liberdade perante um poder público controlador deu o tom da maioria dos casos, seja para garantir a aferição de lucros financeiros, seja para proteger o direito de ir e vir dos indivíduos.

Para ilustrar os achados, serão utilizadas, primeiramente, referências de um exemplo de cada grupo de ações estudadas. Ou seja: uma ADPF proposta por associação de empresários (ADPF 46); uma ADPF proposta por associação de funcionários públicos (ADPF 97); uma ADPF proposta por associação de trabalhadores (ADPF 14); e uma ADPF proposta por associação de profissionais liberais (ADPF 112). Posteriormente, haverá uma passagem breve sobre as outras ações examinadas, tendo como referência os padrões já observados.

$\mathrm{Na}$ ADPF 46, que visava a quebra do monopólio postal da E.C.T (Empresa de correios e telégrafos), a Associação Brasileira das Empresas de Distribuição (ABRAED) estabelece uma correlação 
entre os preceitos fundamentais violados e os objetivos sociais que, segundo ela, norteiam a atuação das empresas associadas. Desse modo, a arguente alega que o funcionamento das empresas vinculadas à associação mantém cerca de um milhão e duzentos mil postos de trabalho, e que elas geram e recolhem impostos, os quais movimentam as atividades públicas do país. Além disso, ela ressalta a ineficiência dos serviços prestados pela ECT em comparação aos serviços das empresas pertencentes à associação, uma vez que as empresas associadas prestam bons serviços, com preços competitivos, geram empregos e pagam regularmente os impostos.

Já a ADPF 97, mobilizada pela Associação Nacional dos Procuradores dos Estados (ANAPE), questiona dispositivo legal paraense que usa os vencimentos dos Procuradores dos Estados como baliza para a remuneração de delegados. Para isso, faz uso do inciso XIII do artigo 37, da Constituição Federal, que ressalta que: "é vedada a vinculação ou equiparação de quaisquer espécies remuneratórias para o efeito de remuneração de pessoal do serviço público." Com isso, os procuradores objetivavam evitar que o aumento nas suas remunerações alcançasse, por derivação, outros funcionários públicos. Como disse o ministro Luís Roberto Barroso, reconhecendo o interesse da associação na ação: "ser paradigma para majoração de vencimentos de outra categoria, evidentemente é um peso para a categoria paradigma, porque uma majoração, por exemplo, de vencimentos que beneficiaria cem, duzentos, trezentos, se você atrela a outra carreira passam a ser mil e duzentos e, aí, é muito mais difícil de conseguir" (Acórdão, p. 39).

Por sua vez, a ADPF número 14, mobilizada pela Confederação Nacional dos Trabalhadores em Transportes Aquaviário, Aéreo, na Pesca e nos Portos (CONTIMAF) contra decreto regulamentador de entidades fechadas de previdência, traz o argumento de que, independentemente de qualquer razão, não competiria ao Estado 
qualquer direito de gestão nos serviços prestados pelas entidades de aposentadoria complementar, haja vista que a Constituição de 1988 não lhe outorga a titularidade de tais direitos, mas sim confere legitimidade à iniciativa de particulares. Como na ADPF 46, evoca-se uma narrativa de liberdade contra a interferência do poder público, em defesa das prerrogativas da própria categoria.

Por fim, na ADPF 112, mobilizada pela Confederação dos Engenheiros Agrônomos do Brasil (CONFAEAB), contra decreto que dispõe sobre o exercício da profissão de Técnico Industrial e Técnico Agrícola de nível médio ou de $2^{\circ}$ grau, a associação requerente assevera que o conteúdo da presente arguição não se restringe a interesse próprio de sua categoria, mas sim, diz respeito a toda a coletividade. Isso porque, segundo a CONFAEAB, a realização de atividades e a execução de funções sem a devida formação acadêmica maculam uma gama de direitos individuais e difusos da coletividade no que tange aos consumidores, à saúde, ao meio ambiente è̀ segurança. A confederação ressalta, ademais, que eles seriam os menos prejudicados em vista de todo o ônus imputado à sociedade em decorrência da realização de suas funções por profissionais não capacitados formalmente.

As ações analisadas representam bem o paradoxo identificado por Rogério Bastos Arantes (2013) na exigência de que as associações de classe proponham ações de controle de constitucionalidade dotadas de "pertinência temática" - isto é, com tema que lhe diga respeito diretamente. Como apelar a um direito constitucional fundamental e que, portanto, é de interesse geral, partindo de uma demanda precipuamente particularista? Em alguns casos, as associações conseguem realizar tal alquimia, representando seu interesse específico como interesse geral. Contudo, em outros casos, o que aparece é uma mera disputa por preservar uma zona de liberdade não restringível por diretrizes políticas ou por outras categorias profissionais em busca de equiparação funcional. 
Interessante notar que nas $\mathrm{ADPF}$ que apresentaram decisão final ou decisão acerca do pedido de liminar foi possível observar divergências nos votos dos ministros, os quais se mostraram mais desconfiados perante a argumentação apresentada pelas associações de empresários que buscavam se apresentar como porta-vozes da sociedade em geral, do que, por exemplo, perante a argumentação das associações de funcionários públicos que trilhavam o mesmo caminho. Nesse sentido, no julgamento da ADPF 46, não obstante as manifestações favoráveis à procedência da ação, como a do relator Marco Aurélio Mello, nos deparamos com posições como a da ministra Ellen Gracie, que destacou que a ABRAED disfarçou os objetivos das empresas associadas ao configurar lesão a princípio constitucional fundamental, visto que as associadas têm o interesse de ficar com a parte menos penosa e mais lucrativa dos serviços de distribuição - o que configuraria, segundo ela, um grave desvirtuamento do "nobre instituto da ADPF" (Acórdão, p. 99). No mesmo sentido, segundo Joaquim Barbosa, as empresas associadas, apenas gostariam de atuar no setor mais lucrativo e de maior interesse econômico, em detrimento da prestação de serviços igualitários e acessíveis a todos os cidadãos (Acórdão p.83-84).

A mesma desconfiança não fora tão forte na ADPF 97, em que os Procuradores buscavam regulamentar os vencimentos de outra categoria profissional. Apesar do Ministro Marco Aurélio Mello ter indagado em que ponto os interesses da categoria profissional congregada pela ANAPE estariam sendo abarcados pelo dispositivo legal questionado, que versava apenas acerca da remuneração dos delegados de polícia, tal entendimento fora vencido. Preponderaram entendimentos como o da ministra Rosa Weber de que "o potencial engessamento remuneratório decorrente do atrelamento de outra categoria a dos Procuradores do Estado do Pará, evidencia o interesse da Associação Nacional dos Procuradores dos Estados em combater 
o que entende configurar afronta à própria norma constitucional" (Acórdão, p. 4).

Nas demais ações analisadas, temos que, dentre as ADPFs de entidades patronais, há em duas delas a mobilização do inciso IV do artigo 7 da Constituição, em sua parte que veda a indexação do salário mínimo para qualquer fim. Na ADPF 95, a Confederação Nacional do Sistema Financeiro (CONSIF), mobiliza tal artigo para se opor a regulamentação do DPVAT (Seguro de Danos Pessoais Causados por Veículos Automotores de Via Terrestre), cuja indenização fora fixada em salários mínimos. Segundo a associação autora da ação, vincular a indenização ao valor do salário mínimo gera grave desequilíbrio financeiro às seguradoras, as quais, incapacitadas de reajustar o custo de seus serviços a essa variação, acabam por ficar suscetíveis às ações mobilizadas contra ela em outras instâncias judiciais. Argumento muito parecido é mobilizado pela Confederação Nacional de Saúde, Hospitais e Estabelecimentos e Serviços (CNS), na ADPF 151, em que, dessa vez, é questionada a vinculação ao salário mínimo do adicional de insalubridade dos técnicos de radiologia. Segundo a proponente, a categoria patronal representada não disporia de condições financeiras sequer para conceder reajustes salariais anualmente, tendo, menos ainda, condições de arcar com incrementos em suas folhas de pagamento oriundos da alteração da base de cálculo do adicional de insalubridade.

Maisumexemploasersomadoaoscasosacimana representação da atuação das associações patronais contra regulações do poder público que interferem na livre gestão de suas atividades empresarias é o da ADPF 127, ajuizada pela Associação Brasileira de Criadores de Camarão (ABCC). Aqui o itinerário seguido é quase o mesmo da ADPF 46, com a associação destacando as diversas contribuições dadas à sociedade pelas empresas que representa, para justificar uma retração das regulamentações dessa atividade por parte do poder 
público. De acordo com a ABCC, o agronegócio do camarão cultivado geraria não só oportunidades de negócios, mas também seria fonte de trabalho, de renda e de divisas. Além disso, essa atividade econômica contribuiria de forma significativa para reduzir as desigualdades sociais e, especialmente, para a reversão do êxodo rural litorâneo, posto que a maior parte dos criadores de camarão seria composta por pequenos produtores que empregam trabalhadores das camadas mais pobres (p. 4 da petição inicial). Os criadores de camarão, no entanto, segundo a associação, não teriam como cumprir seu importante papel social tendo de suportar certas resoluções arbitrárias do Conselho Nacional do Meio Ambiente (CONAMA) acerca da delimitação de áreas de preservação permanente e sobre licenciamento ambiental em terrenos da zona da mata costeira.

No que tange às outras duas ADPFs ajuizadas por associações de funcionários públicos, numa delas, a ADPF 285, podemos observar um padrão de atuação bastante semelhante ao das ADPFs 97 e 112 . Nesse caso, a Federação Brasileira de Associações de Fiscais de Tributos Estaduais (FEBRAFITE) se insurge contra a sobreposição de funções entre as competências de nível médio e de nível superior, de modo que agentes de tributos passaram a exercer algumas funções anteriormente exclusivas à carreira de auditor fiscal - fato que fundamenta pedido de reenquadramento de carreira para agentes de tributos, que estariam encontrando guarida em uma série de decisões do poder Judiciário. Como em outros casos estudados, para evitar estender suas prerrogativas profissionais a outro ramo de trabalhadores, os membros da associação não deixam de salientar que o dispositivo legal questionado acarreta sérios danos não somente à categoria, mas sobretudo, à sociedade, à qual será imputado o ônus do reenquadramento da carreira de agentes de tributos como auditores fiscais (p. 25 da petição inicial). 
Já na outra, a ADPF 90, temos mais uma vez a configuração de uma narrativa de liberdade perante a excessiva regulamentação estatal, desta vez, contudo, mais fortemente vinculada a uma liberdade individual fundamental. Trata-se de ação ajuizada pela Confederação Brasileira de Trabalhadores Policiais Civis (COBRAPOL) contra o Estatuto dos Funcionários Policiais Civis do Estado do Espírito Santo, em sua regra que obriga o policial civil do Estado a "residir no município sede da unidade policial em que prestarem serviços ou onde thes tenha sido permitidos, não podendo afastar-se sem prévia autorização superior, salvo para atos e diligência de seus encargos", o que, no entendimento da Associação, feriria o direito à liberdade de locomoção de seus associados.

Perspectiva semelhante pode ser observada na outra ação de associação de trabalhadores observada. Trata-se da famosa ADPF 54, mobilizada pela Confederação Nacional dos Trabalhadores na Saúde (CNTS), visando a permissão de interrupção de gravidez de feto anencéfalo, sem que o trabalhador da saúde responsável pelo procedimento fosse enquadrado no crime de aborto. Ainda que visando construir uma narrativa de liberdade em proveito dos membros da associação contra o excessivo intervencionismo estatal, temos que essas duas últimas ações apresentam um caráter menos utilitarista, que não visa proteger a liberdade como forma de redução de prejuízos financeiros, mas como garantia de não ser injustamente tolhido em seu direito de ir e vir. Contudo, num universo de 10 ações analisadas, essas duas ações parecem mais próximas de representarem uma exceção do que a regra do uso das ADPFs pelas entidades de classe.

\section{Conclusão}

A hipótese que originou a pesquisa foi a de que a utilização das ADPFs estaria condicionada pelos interesses das diferentes 
classes sociais e grupos econômicos inseridos na disputa em torno do significado do texto constitucional, ressaltando como fundamentais os preceitos que dão maior guarida aos seus interesses, em leituras, por exemplo, mais liberais ou mais estatistas da Constituição. Contudo, o que os resultados da pesquisa mostraram foram dois padrões comuns de atuação, que são a atuação em busca da desregulamentação estatal - especialmente na atuação das associações de empresários contra o Poder Executivo Federal - e a atuação com vistas a garantir acesso privilegiado a recursos escassos - especialmente na atuação de associações de funcionários públicos, contra os Poderes Judiciários estaduais. Ainda que em algumas ações a liberdade seja defendida enquanto direito de ir e vir de cidadãos, o mais comum, no entanto, é que ela seja mobilizada para evitar prejuízos econômicos atuais ou potenciais da categoria que ajuíza a ação.

Ao menos no que tange às ações aqui analisadas, quando grupos empresariais defendem a liberdade de realização de seus empreendimentos, livres das amarras de decretos do poder Executivo, o fazem apelando também ao fato de gerarem empregos, impostos, desenvolvimento econômico do país, etc. Contudo, em ações em que tem destaque a lógica de disputa por recursos escassos, não costuma haver a construção de uma narrativa de interesse público, mas, curiosamente, tampouco há desconfiança perante a existência desse interesse público por parte dos ministros do STF, contrariamente ao que acontece em ações movidas por associações de empresários, em que os ministros se mostram bastante reticentes quanto à aceitação de tais agentes como porta-vozes do interesse público e não como perseguidores de seus interesses privados.

No primeiro caso, observa-se o movimento de "sinédoque" da hegemonia, em que uma parte da sociedade tenta se colocar como representante da sociedade como um todo, fazendo de um interesse, em tese, corporativo, a representação de um valor universal. Todavia, 
no segundo, a demanda é, nesse sentido, menos politizada, pois menos voltada para a formação de uma identidade coletiva que transcende a demanda, sendo tomada como mero exercício de subsunção do caso à regra jurídica. Provavelmente, isto é tanto mais possível quanto menos é necessário a construção de um horizonte comum por meio da representação dos interesses corporativos como interesses gerais. Como é de se supor, isso acontece quando esse horizonte comum é compartilhado entre litigantes e julgadores, o que não é o caso das ações de empresários e trabalhadores, mas tende a ser no caso das ações de funcionários públicos, cujas categorias de percepção de mundo - seu habitus, para fazer uso da categoria de Bourdieu (2006, p. 231) - estariam mais próximas das dos próprios ministros. Não à toa, segundo Costa e Benvindo (2014, p. 67), não obstante o baixo índice de sucesso das associações profissionais na proposição de ADINs, "corporações ligadas ao Sistema de Justiça", tiveram "tantas decisões procedentes quanto todas as decisões procedentes obtidas pelas entidades corporativas de empresas" e "se incluirmos no Sistema de Justiça também a polícia, então esse número seria maior do que a de todos os governadores de estados reunidos" ${ }^{12}$ Nesse caso, poder-se-ia considerar que, para corporações ligadas ao Sistema de Justiça, a busca da hegemonia pela via judicial, já encontra parte de seu caminho pavimentado antes mesmo da mobilização do espaço jurídico, justificando a racionalidade do uso estratégico da arena judicial como locus de ação política para a consecução de seus interesses corporativos, já presumidos como também interesses gerais e, por conseguinte, constitucionalmente protegidos.

Contudo, no que tange aos motivos para o alto índice de busca da hegemonia política no judiciário por parte de outras associações de classe, ainda há muito de obscuro e os dados presentes neste

12 Lembrando que os governadores de estados, junto ao Procurador Geral da República, são os propositores de ADINs com maior índice de sucesso (HARTMAN; FERREIRA; REGO, 2016). 
estudo têm pouco a contribuir a esse respeito. Afinal, não se trata de um caminho promissor em termos de sucesso das demandas, ou de velocidade de respostas. Muito provavelmente, tal meio é mobilizado como "mais um" dentre várias outras formas de pressão, por exemplo, nas vias legislativas tradicionais. Afinal, como destaca McCann (2008, p. 523), a litigância é apenas uma dimensão potencial ou fase de uma disputa dinâmica, maior e mais complexa do que isso. Não por acaso, muitas demandas de controle de constitucionalidade perdem seu objeto à época de seu julgamento pelo fato de a legislação questionada, àquela altura, já ter sido alterada. Sendo grupos forçados a certa prestação de contas a seus afiliados, as associações de classe devem se ver compelidas a agir por todos os meios possíveis abertos a ela, ainda que, como no caso do controle de constitucionalidade das leis, trate-se de meio muitas vezes pouco receptivo às suas demandas e à sinédoque constitucional que transforma seus interesses particulares em representações de princípios jurídicos gerais e valores coletivos ao menos quando tais associações não agregam servidores da justiça.

\section{REFERÊNCIAS}

ARANTES, Rogério Bastos. Cortes constitucionais. In: AVRITZER, Leonardo et al. Dimensões políticas da justiça. Rio de Janeiro: Civilização Brasileira, 2013. p. 195-206.

ASENSI, Felipe Dutra. Juridicização das relações sociais e Ministério Público: novas estratégias e desafios na efetivação do direito à saúde. 2008. 211 f. Dissertação (Mestrado em Sociologia) - Instituto Universitário de Pesquisas do Rio de Janeiro, Universidade Cândido Mendes, Rio de Janeiro. 2008.

BARROSO, Luís Roberto. O controle de constitucionalidade no direito brasileiro: exposição sistemática da doutrina e análise crítica da jurisprudência. 3. ed. São Paulo: Saraiva, 2008.

BOURDIEU, Pierre. A força do Direito: elementos para uma sociologia crítica do campo jurídico. In: BOURDIEU, Pierre. O poder simbólico. 9. ed. Rio de Janeiro: Bertrand Brasil, 2006. p. 209-254.

BRASIL. Supremo Tribunal Federal - STF. Argüição de descumprimento de preceito fundamental: ADPF 97 PA. Relatora: Min. Rosa Weber, Julgamento:21 ago. 2014. 
Disponível em: <http://stf.jusbrasil.com.br/jurisprudencia/25342189/arguicao-dedescumprimento-de-preceito-fundamental-adpf-97-pa-stf $>$. Acesso em: 15 out. 2015.

COSTA, Alexandre Araújo; BENVINDO, Juliano Zaiden. A quem interessa o controle concentrado de constitucionalidade? 2014. Disponível em: <http://www.ufjf.br/ siddharta legale/files/2014/07/Alexandra-Costa-e-Juliano-Zaiden-a-quem-interessa-o-controle.pdf $>$. Acesso em: 15 out. 2015.

DWORKIN, Ronald. Levando os direitos a sério. São Paulo: Martins Fontes, 2002.

HÄBERLE, Peter. Hermenêutica Constitucional: a sociedade aberta dos intérpretes da constituição: contribuição para a interpretação pluralista e "procedimental" da constituição. Porto Alegre: Sergio Antonio Fabris, 2002.

HARTMAN, Ivar Alberto Martins; FERREIRA, Lívia da Silva; REGO, Bianca Dutra da Silva. Deferência ao fiscal da lei? A probabilidade de sucesso do PGR nas ações diretas de inconstitucionalidade. Revista de Estudos Empíricos em Direito, Ribeirão Preto, v. 3, n. 1, p. 160-171. jan. 2016.

HIRSCHL, Ran. The judicialization of politics. In: WHTTINGTON, Keith E.; KELEMEN, R. Daniel; CALDEIRA, Gregory A. (Ed.). Oxford handbook of law and politics. Oxford: Oxford University Press, 2008. p. 119-140.

KOERNER, Andrei; INATOMI, Celly Cook; BARATTO, Márcia. Sobre o Judiciário e a judicialização. In: ARAÚJO, Gisele et al. (Org.) O Estado democrático de direito em questão: teorias críticas da judicialização da política. São Paulo: Elsevier, 2011. p. 149-180.

LACLAU, Ernesto; MOUFFE, Chantal. Hegemonía y estrategia socialista: hacia una radicalización de la democracia. 2. ed. Buenos Aires: Fondo de Cultura Económica de Argentina, 2006.

LOSEKANN, Cristiana. Mobilização do direito como repertório de ação coletiva e crítica institucional no campo ambiental brasileiro. Dados, Rio de Janeiro, v. 56, n. 2, p. 311-349. abr./jun. 2013.

MACIEL, Débora Alves. Ação Coletiva, mobilização do direito e instituições políticas: o caso da Campanha da Lei Maria da Penha. Revista Brasileira de Ciências Sociais, São Paulo, v. 26, n. 77, p. 97-111, out. 2011.

MACIEL, Débora Alves; KOERNER, Andrei. Sentidos da judicialização da política: duas análises. Lua Nova, São Paulo, n. 57, p. 113-134, 2002.

McCANN, Michael. Litigation and legal mobilization. In: WHTTINGTON, Keith E.; KELEMEN, R. Daniel; CALDEIRA, Gregory A. (Ed.) Oxford handbook of law and politics. Oxford: Oxford University Press, 2008. p. 522-540. 
POGREBINSCHI, Thamy. Judicialização ou representação? Política, direito e democracia no Brasil. Rio de Janeiro: Elsevier, 2012.

TATE, Chester Neal; VALLINDER, Torbjörn (Ed.) The global expansion of judicial power. New York: New York University Press, 1995.

VIANNA, Luiz Werneck et al. A judicialização da política e das relações sociais no Brasil. Rio de Janeiro: Revan, 1999.

VIANNA, Luiz Werneck; BURGOS, Marcelo. Revolução processual do direito e democracia progressiva. In: VIANNA, Luiz Werneck (Org.). A democracia e os três poderes no Brasil. Belo Horizonte: UFMG. 2003. p. 337-491. 